\title{
A Comparison in Transportation Infrastructure between China and Other Countries
}

\author{
Yuan-cheng $\mathrm{HE}^{1, \mathrm{a},{ }^{*}}$ \\ ${ }^{1}$ School of economics and management, Huizhou University, Huizhou, China \\ aheyuancheng@163.com
}

Keywords: Logistics infrastructure, Average indicators, Factoring analysis.

\begin{abstract}
Comparing 148 countries' z-scores resulting with the Factoring Analysis, the paper verifies that a big gap still exists between China and other advanced countries based on 6 average indicators calculated from CIA statistics in transportation, although China's infrastructure has been considerably improving in both quality and quantity in the past three decades. As a result, the paper advises that keeping increasing the investment in traffic is necessary, particularly in the current situation that Chinese economy is in a depression.
\end{abstract}

\section{Introduction}

In the past more than 3 decades, Chinese economy has increased rapidly and surpassed some established developed countries in economic aggregates at a surprising speed. Until 2010, China had replaced Japan to be the second largest economic entity on Earth. Under such a background, there has existed misleading views of point in the academia that China is already a superpower and an advanced country and the like, neglecting the fact that the majority of basic economic indicators per capita are much lower than the average levels of the world. To identify China's precise and real situation and figure out the gap in traffic infrastructure from developed countries and even other developing ones in the world, the paper first presents several average indicators which are easily available in Chinese National Statistical Bureau to demonstrate the great changes that China has achieved in traffic infrastructure. And then the article makes the Principal Component Analysis (PCA) on 6 average transportation indicators of 151 countries computed from statistical data on CIA website after considering their populations. Afterwards, by visualizing the z-scores of every country, a radar chart shows a relative position of China in the world clearly.

\section{Methodology}

In order to assess the current situation of China's transportation infrastructure, it is necessary to look for a group of appropriate indicators. Furthermore, removing the overlapping information loaded on every indicator during applying them to assess is a prerequisite for its success. The Factoring Component Analysis(FCA) and its Principal Component Analysis( PCA) of the statistics software SPSS utilized in this essay are popular and efficient while dealing with a set of invariables which may be relevant and carry similar or repeated information, and with FCA or PCA, the independent indicators in replace of the original ones can be singled out . After that, in order to position China in logistics infrastructure in the world, it also adopts the method of ranking $\mathrm{z}$-score of each case computed from their factoring scores.

Most data in this article is from Central Intelligence Agency of USA, except some 
smaller part of it from National Statistical Bureau of China like the numbers of airports, heliports and roadways in three years including 1984, 1999 and 2014. Based on those indicators and the population of China and other countries, the article is designed to utilize 5 average transportation indicators as a unit of per million people. Furthermore, combining other related indicator like income per capita, these 6 indicators may reflect the basic situation of one country in traffic or transportation .Meanwhile, whether or not an indicator is chosen also considerably depends on its availability or not.

Among statistics, two categories are seen frequently: one is absolute values which are related to the size or scale of things, and the other with relative ones, like averages. Obviously, the former indicators can demonstrate the total transportation scale of a region or country and the latter are related to the likes of efficiency, productivity and the quality of life, which present the real development levels of one country. In this paper, there are 6 derived indicators like GDPPC(GDP per capita), APMP(airports per a million people), $P$ PMP(pipelines per a million people),RPMP(railways per a million people), ROPMP(roadways per a million people),WPMP(waterways per a million people) which are averaged out from the original data from CIA and standardized so as to be analyzed in PCA analysis. The sample of the article almost includes all important countries in the world whose sizes are no less than Brunei and the total number is 148 sovereign nations and the European Union. And most data is directly and indirectly from the World Factbook of 2016 on the website of CIA.

\section{Analyzing Methods}

The Factoring Analysis of SPSS is a main studying method the paper employs, apart from a comparative method at the end of it. The two approaches are not only simple but also practicable. At the end of the article, a comparison among the 148 sovereign states is used so as to attain each other's position in the world.

\section{Data and Diagrams}

Table 1 and table 2 are increases of China's transportation infrastructure in three different years of 1984, 1999 and 2014, at 15-year intervals. Consequently, they basically reflect its basic situations in different periods of time.

Table 1. Increases of China in 4 modes of transportation

\begin{tabular}{|c|c|c|c|}
\hline \multirow{2}{*}{$\begin{array}{c}\text { Modes of } \\
\text { transport }\end{array}$} & \multicolumn{3}{|c|}{ years } \\
\cline { 2 - 4 } & 1984 & 1999 & 2014 \\
\hline airports & 88 & 142 & 200 \\
\hline railways & 5.48 & 6.74 & 11.18 \\
\hline waterways & 10.93 & 11.65 & 12.63 \\
\hline pipelines & 1.1 & 2.47 & 10.57 \\
\hline
\end{tabular}

To identify the transportation increase of China, this table lists lengths of 4 modes of transportation every 15 years. Obviously, in the past three decades, China's growth in transportation is large-scale. For instance, the length of pipelines in 2014 was almost tenfold bigger than that of the year of 1984, and the railway and airport had a twofold increase. In terms of that fact, Chinese achievement in the infrastructure field is undoubtedly outstanding.

Meanwhile, there are similar situations with other indicators in the following: 
Table 2. Increases a million people in different modes of transportation in the same three years

\begin{tabular}{|l|l|l|l|l|l|l|l|}
\hline \multirow{2}{*}{ Year } & \multicolumn{7}{|c|}{ indicators } \\
\cline { 2 - 8 } & $\begin{array}{l}\text { Population } \\
\text { (billion) }\end{array}$ & GDPPC & APMP & PPMP & RPMP & ROPMP & WPMP \\
\hline 1984 & 1.04 & 698 & 0.084 & 0.001 & 0.005 & 0.089 & 0.010 \\
\hline 1999 & 1.26 & 7105 & 0.004 & 0.002 & 0.005 & 0.107 & 0.009 \\
\hline 2014 & 1.37 & 47080 & 0.068 & 0.008 & 0.008 & 0.326 & 0.010 \\
\hline
\end{tabular}

In a sense, China is surely a successful case in transportation construction. However, the whole world is keeping going forward. Furthermore, the concept of development is relative and dynamic instead of being static, keeping updated. Only compared to other countries in the world, it may be possible to have a precise insight into China's growth in infrastructure. The table 3 is calculated from the website of CIA.

Table 3-1. 6 Indicators of 148 countries from GDP per capita to WPMP

\begin{tabular}{|c|c|c|c|c|c|c|}
\hline \multirow{2}{*}{ countries } & \multicolumn{6}{|c|}{ indicators } \\
\hline & GDPPC & APMP & PPMP & RPMP & ROPMP & WPMP \\
\hline Brunei & 79700 & 2 & 2907 & 0 & 7050 & 486 \\
\hline Burma & 5500 & 1 & 80 & 89 & 610 & 227 \\
\hline Cambodia & 3500 & 1 & 0 & 41 & 2846 & 236 \\
\hline China & 14100 & 0 & 61 & 140 & 3003 & 80 \\
\hline Indonesia & 11100 & 1 & 86 & 32 & 1940 & 84 \\
\hline Japan & 38100 & 1 & 37 & 215 & 9603 & 14 \\
\hline North Korea & 1800 & 3 & 0 & 298 & 1023 & 90 \\
\hline South Korea & 36500 & 2 & 66 & 70 & 2137 & 33 \\
\hline Laos & 5300 & 6 & 78 & 0 & 5728 & 666 \\
\hline Malaysia & 26300 & 4 & 297 & 61 & 4732 & 236 \\
\hline Mongolia & 12100 & 15 & 0 & 606 & 16455 & 194 \\
\hline Philippines & 7300 & 2 & 9 & 10 & 2142 & 32 \\
\hline Vietnam & 6000 & 0 & 9 & 28 & 2072 & 500 \\
\hline \multicolumn{7}{|l|}{ Central Asia } \\
\hline Kazakhstan & 24300 & 5 & 1429 & 781 & 5365 & 220 \\
\hline Kyrgyzstan & 3400 & 5 & 88 & 83 & 6002 & 106 \\
\hline Russia & 25400 & 9 & 1825 & 612 & 9011 & 716 \\
\hline Tajikistan & 2700 & 3 & 72 & 83 & 3390 & 24 \\
\hline Turkmenistan & 16400 & 5 & 1721 & 570 & 11200 & 248 \\
\hline Uzbekistan & 6100 & 2 & 389 & 125 & 2962 & 38 \\
\hline \multicolumn{7}{|l|}{ South Asia } \\
\hline India & 6200 & 0 & 29 & 55 & 3754 & 12 \\
\hline Bangladesh & 3600 & 0 & 17 & 15 & 126 & 0 \\
\hline Afghanistan & 3600 & 1 & 13 & 0 & 1195 & 34 \\
\hline Bhutan & 8200 & 3 & 0 & 0 & 14258 & 0 \\
\hline Pakistan & 5000 & 1 & 82 & 60 & 1326 & 0 \\
\hline Nepal & 2500 & 1 & 0 & 2 & 344 & 0 \\
\hline Sri Lanka & 10600 & 1 & 0 & 66 & 5173 & 7 \\
\hline
\end{tabular}


Table 3-2. 6 Indicators of 148 countries from GDP per capita to WPMP

\begin{tabular}{|c|c|c|c|c|c|c|}
\hline \multicolumn{7}{|l|}{ Middle East } \\
\hline Armenia & 8500 & 4 & 731 & 255 & 2549 & 0 \\
\hline Azerbaijan & 18000 & 4 & 657 & 211 & 5413 & 0 \\
\hline Georgia & 9600 & 4 & 562 & 276 & 3875 & 0 \\
\hline Iran & 17300 & 4 & 252 & 104 & 2430 & 10 \\
\hline Iraq & 15500 & 3 & 282 & 61 & 1609 & 142 \\
\hline Israel & 33700 & 6 & 132 & 155 & 2307 & 0 \\
\hline Jordan & 12100 & 2 & 64 & 62 & 887 & 0 \\
\hline Kuwait & 70200 & 3 & 308 & 0 & 2370 & 0 \\
\hline Lebanon & 18200 & 1 & 14 & 65 & 1127 & 0 \\
\hline Oman & 44600 & 40 & 2490 & 0 & 18324 & 0 \\
\hline Qatar & 132100 & 3 & 1745 & 0 & 4479 & 0 \\
\hline Saudi Arabia & 53600 & 8 & 371 & 50 & 7977 & 0 \\
\hline Syria & 5100 & 5 & 305 & 120 & 4095 & 53 \\
\hline Turkey & 20400 & 1 & 197 & 151 & 4857 & 15 \\
\hline United Arab Emirates & 67600 & 7 & 1339 & 0 & 706 & 0 \\
\hline Yemen & 2700 & 2 & 76 & 0 & 2667 & 0 \\
\hline Australia & 65400 & 21 & 1524 & 1625 & 36184 & 88 \\
\hline New Zealand & 36200 & 28 & 594 & 930 & 21382 & 0 \\
\hline Fuji & 9000 & 31 & 0 & 656 & 3783 & 223 \\
\hline Canada & 45600 & 42 & 2849 & 2220 & 29695 & 18 \\
\hline United States & 55800 & 42 & 6924 & 913 & 20495 & 128 \\
\hline Mexico & 17500 & 14 & 304 & 126 & 3102 & 24 \\
\hline Argentina & 22600 & 26 & 918 & 850 & 5327 & 253 \\
\hline Bolivia & 6500 & 79 & 893 & 324 & 7452 & 926 \\
\hline Brazil & 15600 & 20 & 132 & 140 & 7740 & 245 \\
\hline Chile & 23500 & 27 & 323 & 416 & 4442 & 0 \\
\hline Colombia & 13800 & 18 & 326 & 46 & 4383 & 529 \\
\hline Ecuador & 11300 & 27 & 268 & 61 & 2752 & 95 \\
\hline Guyana & 7500 & 159 & 0 & 0 & 10840 & 449 \\
\hline Paraguay & 8700 & 118 & 0 & 4 & 4726 & 457 \\
\hline Peru & 12200 & 6 & 133 & 61 & 4621 & 289 \\
\hline Suriname & 16300 & 95 & 86 & 0 & 7425 & 2070 \\
\hline Uruguay & 21500 & 40 & 125 & 491 & 23260 & 479 \\
\hline Venezuela & 16700 & 15 & 556 & 15 & 3286 & 243 \\
\hline Albania & 11900 & 1 & 191 & 223 & 5942 & 14 \\
\hline Austria & 47300 & 6 & 641 & 608 & 15417 & 41 \\
\hline Belarus & 17700 & 7 & 908 & 576 & 9009 & 261 \\
\hline Belgium & 43600 & 4 & 338 & 317 & 13601 & 180 \\
\hline $\begin{array}{l}\text { Bosnia and } \\
\text { Herzegovina }\end{array}$ & 10500 & 6 & 40 & 250 & 5929 & 0 \\
\hline Bulgaria & 19100 & 613 & 32567 & 46122 & 175976 & 4239 \\
\hline Croatia & 21600 & 15 & 676 & 610 & 6038 & 176 \\
\hline Cyprus & 32800 & 13 & 0 & 0 & 16823 & 0 \\
\hline Czech Republic & 31600 & 12 & 732 & 904 & 12275 & 62 \\
\hline
\end{tabular}


Table 3-3. 6 Indicators of 148 countries from GDP per capita to WPMP

\begin{tabular}{|c|c|c|c|c|c|c|}
\hline Denmark & 45700 & 14 & 902 & 472 & 13347 & 72 \\
\hline Estonia & 28600 & 14 & 686 & 945 & 46160 & 265 \\
\hline European Union & 37800 & 6 & 0 & 449 & 20591 & 104 \\
\hline Finland & 41100 & 27 & 308 & 1081 & 82893 & 1461 \\
\hline France & 41200 & 7 & 351 & 445 & 15453 & 128 \\
\hline Germany & 46900 & 7 & 425 & 538 & 7977 & 92 \\
\hline Greece & 26400 & 7 & 132 & 236 & 10854 & 1 \\
\hline Hungary & 26200 & 4 & 2107 & 813 & 20571 & 164 \\
\hline Ireland & 55500 & 8 & 439 & 662 & 19630 & 195 \\
\hline Iceland & 46100 & 289 & 0 & 0 & 38835 & 0 \\
\hline Italy & 35700 & 2 & 371 & 326 & 7885 & 39 \\
\hline Latvia & 24700 & 21 & 575 & 1127 & 36462 & 151 \\
\hline Lithuania & 28400 & 21 & 708 & 613 & 29179 & 153 \\
\hline Luxembourg & 99000 & 4 & 296 & 482 & 5084 & 65 \\
\hline Macedonia & 1400 & 5 & 185 & 333 & 6766 & 0 \\
\hline Moldova & 5000 & 2 & 537 & 330 & 2637 & 157 \\
\hline Montenegro & 16100 & 8 & 0 & 386 & 11996 & 0 \\
\hline Netherlands & 49200 & 2 & 584 & 190 & 8180 & 368 \\
\hline Norway & 68400 & 18 & 2535 & 816 & 18025 & 303 \\
\hline Poland & 26500 & 3 & 424 & 514 & 10685 & 104 \\
\hline Portugal & 27800 & 6 & 143 & 284 & 7658 & 19 \\
\hline Romania & 20800 & 2 & 285 & 520 & 3886 & 80 \\
\hline Serbia & 13700 & 4 & 0 & 531 & 6165 & 82 \\
\hline Slovakia & 29700 & 6 & 1321 & 666 & 10077 & 32 \\
\hline Slovenia & 31000 & 8 & 428 & 620 & 19656 & 0 \\
\hline Spain & 34800 & 3 & 302 & 334 & 14190 & 21 \\
\hline Sweden & 47900 & 24 & 166 & 1216 & 59129 & 209 \\
\hline Switzerland & 58600 & 8 & 234 & 696 & 8799 & 159 \\
\hline Ukraine & 7500 & 4 & 1026 & 489 & 3819 & 38 \\
\hline United Kingdom & 41200 & 7 & 621 & 263 & 6154 & 50 \\
\hline Algeria & 1450 & 4 & 750 & 100 & 2874 & 0 \\
\hline Anglo & 7300 & 9 & 77 & 145 & 2621 & 66 \\
\hline Benin & 2100 & 1 & 0 & 42 & 1531 & 14 \\
\hline Botswana & 16400 & 34 & 0 & 407 & 8208 & 0 \\
\hline Burkina Faso & 1700 & 1 & 0 & 33 & 807 & 0 \\
\hline Burundi & 800 & 1 & 0 & 0 & 1147 & 0 \\
\hline Cameroon & 3100 & 1 & 51 & 42 & 2163 & 0 \\
\hline $\begin{array}{l}\text { Central African } \\
\text { Republic }\end{array}$ & 600 & 7 & 0 & 0 & 3761 & 519 \\
\hline Chad & 2600 & 5 & 50 & 0 & 3439 & 0 \\
\hline $\begin{array}{l}\text { the Democratic } \\
\text { Republic of Congo }\end{array}$ & 800 & 2 & 11 & 50 & 1934 & 189 \\
\hline the Republic of Congo & 6700 & 6 & 256 & 107 & 3575 & 236 \\
\hline Cote D'Ivoire & 3300 & 1 & 21 & 28 & 3520 & 42 \\
\hline Djibouti & 3200 & 16 & 0 & 121 & 3700 & $\overline{0}$ \\
\hline Egypt & 11800 & 1 & 178 & 57 & 1553 & 40 \\
\hline
\end{tabular}


Table 3-4. 6 Indicators of 148 countries from GDP per capita to WPMP

\begin{tabular}{|c|c|c|c|c|c|c|}
\hline Equatorial Guinea & 31800 & 9 & 266 & 0 & 3888 & 0 \\
\hline Eritrea & 1300 & 2 & 0 & 47 & 614 & 0 \\
\hline Ethiopia & 1800 & 1 & 0 & 7 & 1110 & 0 \\
\hline Gabon & 18600 & 26 & 1436 & 381 & 5377 & 938 \\
\hline Gambia, & 1600 & 1 & 0 & 0 & 1901 & 198 \\
\hline Ghana & 4300 & 0 & 29 & 36 & 4160 & 49 \\
\hline Guinea & 1200 & 1 & 0 & 53 & 3765 & 110 \\
\hline Guinea-Bissau & 1500 & 5 & 0 & 0 & 2002 & 0 \\
\hline Kenya & 3200 & 4 & 20 & 73 & 3503 & 0 \\
\hline Lesotho & 3000 & 12 & 0 & 0 & 3050 & 0 \\
\hline Liberia & 900 & 7 & 1 & 102 & 2526 & 0 \\
\hline Libya & 14600 & 23 & 1814 & 0 & 15600 & 0 \\
\hline Madagascar & 1500 & 3 & 0 & 35 & 1574 & 25 \\
\hline Malawi & 1100 & 2 & 0 & 43 & 860 & 39 \\
\hline Mali & 2200 & 1 & 0 & 35 & 0 & 106 \\
\hline Mauritania & 4400 & 8 & 0 & 202 & 2955 & 0 \\
\hline Morocco & 8200 & 2 & 0 & 62 & 1752 & 0 \\
\hline Mozambique & 1200 & 4 & 49 & 189 & 1199 & 18 \\
\hline Namibia & 11400 & 51 & 0 & 1188 & 19951 & 0 \\
\hline Niger & 1100 & 2 & 0 & 0 & 1050 & 17 \\
\hline Nigeria & 6100 & 0 & 46 & 21 & 1064 & 47 \\
\hline Rwanda & 1800 & 1 & 0 & 0 & 371 & 0 \\
\hline Senegal & 2500 & 1 & 4 & 65 & 1073 & 72 \\
\hline Sierra Lion & 1600 & 1 & 0 & 0 & 1922 & 136 \\
\hline Somalia & 400 & 6 & 0 & 0 & 2082 & 0 \\
\hline South Africa & 13200 & 11 & 72 & 391 & 13917 & 0 \\
\hline South Sudan & 2000 & 7 & 0 & 21 & 581 & 0 \\
\hline Swaziland & 8500 & 10 & 0 & 210 & 2503 & 0 \\
\hline Tanzania & 2900 & 3 & 24 & 89 & 1694 & 0 \\
\hline Togo & 1500 & 1 & 0 & 75 & 1543 & 7 \\
\hline Tunisia & 11400 & 3 & 454 & 197 & 1759 & 0 \\
\hline Uganda & 2000 & 1 & 0 & 34 & 539 & 0 \\
\hline Western Sahara & 2500 & 11 & 0 & 0 & 0 & 0 \\
\hline Zambia & 3900 & 6 & 51 & 207 & 2685 & 149 \\
\hline Zimbabwe & 2100 & 14 & 0 & 241 & 6836 & 0 \\
\hline
\end{tabular}

\section{The Procedures of PCA}

For the chosen 6 indicators, there is a possibility that they are correlated to some extent. In order to remove this kind of overlapping information in different indicators, the Factoring Component Analysis (FCA) is introduced into this article, especially its Principal Component Analysis (PCA) and all the analysis is finished by the software SPSS 19. 


\section{Check the Correlation Matrix}

$$
R=\left(r_{i j}\right)_{m \times m}
$$

$r_{i j}$ among the matrix is the correlated coefficient between $\mathrm{x}_{\mathrm{j}}$ and $\mathrm{x}_{\mathrm{j}}$.

Firstly, to test whether or not it is necessary to use the principal component analysis of SPSS, the correlational matrix of the six indicators should be presented in table 4:

Table 4. Correlation Matrix

\begin{tabular}{|c|c|c|c|c|c|c|c|}
\hline & & GDP PC(ppp) & Apmp & PPMP & Rpmp & Ropmp & WPMP \\
\hline \multirow{6}{*}{ 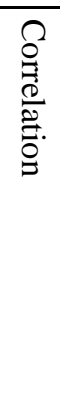 } & $\begin{array}{l}\text { GDP } \\
\text { PC(ppp) }\end{array}$ & 1.000 & .057 & .140 & .035 & .252 & .037 \\
\hline & Apmp & .057 & 1.000 & .826 & .851 & .774 & .767 \\
\hline & PPMP & .140 & .826 & 1.000 & .965 & .793 & .779 \\
\hline & Rpmp & .035 & .851 & .965 & 1.000 & .815 & .796 \\
\hline & Ropmp & .252 & .774 & .793 & .815 & 1.000 & .733 \\
\hline & WPMP & .037 & .767 & .779 & .796 & .733 & 1.000 \\
\hline
\end{tabular}

Apparently, there are some correlational relations between each other .As a result , the principal component analysis can play a role in removing repeatedly redundant information from data so as to simplify data analysis.

\section{KMO and Bartlett's Test}

Whether partial correlations among variables are small is known by the Kaiser-Meyer-Olkin measure of sampling adequacy tests. And Bartlett's test of sphericity tests whether the correlation matrix is an identity one, which indicates the factor model is inappropriate. KMO must be greater than 0.5 , and the range $0.8-0.9$ is very appropriate for factor analysis. And the Bartlett's test of sphericity is significant. That means that its associated probability is less than 0.05 .

With the help of SPSS 19.0, we get KMO and Bartlett's Test of the matrix in table 5: $\mathrm{KMO}=0.8$, and Bartlett's Test is significant, its probability is less than 0.005. So it means our data matrix is suitable for PCA analysis.

Table 5. KMO and Bartlett's Test

\begin{tabular}{|l|l|l|}
\hline \multicolumn{2}{|l|}{ Kaiser-Meyer-Olkin Measure of Sampling Adequacy } & .800 \\
\hline Bartlett's Test of Sphericity & Approx. Chi-Square & 948.743 \\
\hline & Df. & 15 \\
\hline & Sig. & .000 \\
\hline
\end{tabular}

The table 6: communities, shows extraction information rates of the variable of source data (extraction method: principal component analysis), and these rates are very high except the information extraction of $\mathrm{x} 1$, which also tests the principal component analysis is right.

The first variance contribution rate is high than $71 \%$, furthermore its initial eigenvalue 4.26 is greater than 1 as is shown in table 7 . On the other hand, eigenvalue is no less than 1 is one important principle of determining component, and that is because the chosen principal component, while its eigenvalue is less than 1 , is not 
better than the original variable in explaining the information of the original data. Our source data satisfy the two criteria of choosing components.

Table 6. Communities

\begin{tabular}{|ccc|}
\hline & Initial & Extraction \\
\hline GDP PC(ppp) & 1.000 & .990 \\
\hline Apmp & 1.000 & .843 \\
\hline PPMP & 1.000 & .903 \\
\hline Rpmp & 1.000 & .934 \\
\hline Ropmp & 1.000 & .831 \\
\hline WPMP & 1.000 & .787 \\
\hline Extraction Method: Principal Component Analysis. \\
\hline
\end{tabular}

Table 7. Total Variance Explained

\begin{tabular}{|c|c|c|c|c|c|c|}
\hline \multirow{2}{*}{ Component } & \multicolumn{3}{|c|}{ Initial Eigenvalues } & \multicolumn{3}{c|}{ Extraction Sums of Squared Loadings } \\
\cline { 2 - 7 } & Total & $\%$ of Variance & $\begin{array}{c}\text { Cumulative } \\
\%\end{array}$ & Total & \% of Variance & $\begin{array}{c}\text { Cumulative } \\
\%\end{array}$ \\
\hline 1 & 4.260 & 71.006 & 71.006 & 4.260 & 71.006 & 71.006 \\
\hline 2 & 1.027 & 17.120 & 88.127 & 1.027 & 17.120 & 88.127 \\
\hline 3 & .269 & 4.476 & 92.602 & & & \\
\hline 4 & .222 & 3.702 & 96.304 & & & \\
\hline 5 & .196 & 3.264 & 99.568 & & & \\
\hline 6 & .026 & .432 & 100.000 & & & \\
\hline
\end{tabular}

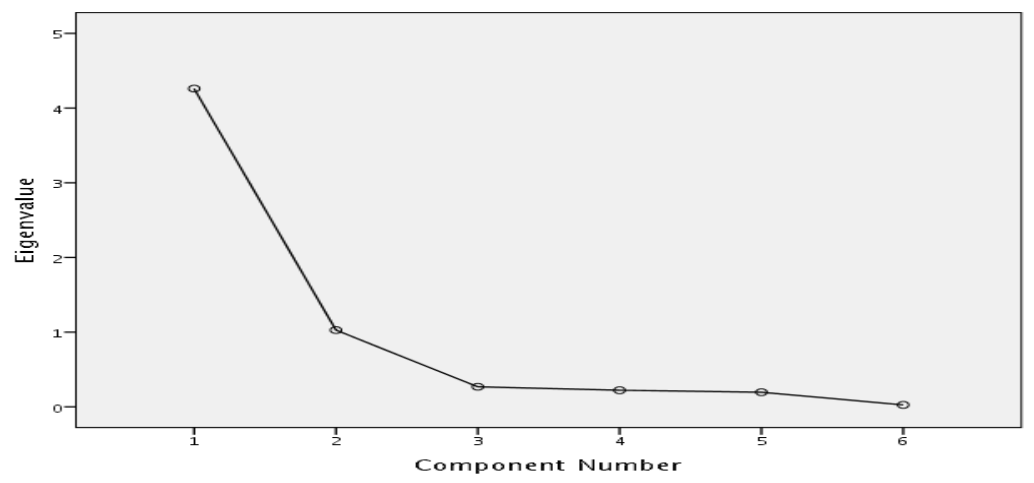

Figure. 1. Scree Plot

According to the scree plot in Figure.1, there are not only apparent differences among the first two principal components and other components, but their eigenvalues are more than 1, conversely eigenvalues of the left components are greatly less than 1, which do not satisfy the requirement of choosing principal component. As a result, the first two components are chosen as principal components.

\section{Principal Components}

According to the component score coefficient matrix in table 8, the computable formula can be gotten:

Factor $1=-0.062 \times 1+0.222 \times 2+0.222 \times 3+0.235 \times 4+0.194 \times 5+0.216 \times 6$

Factor $2=0.957 \times 1-0.063 \times 2+0.018 \times 3-0.083 \times 4+0.177 \times 5-0.088 \times 6$ 
Table 8. Component Score Coefficient Matrix

\begin{tabular}{|ccc|}
\hline & \multicolumn{2}{c|}{ Component } \\
\cline { 2 - 3 } & 1 & 2 \\
\hline GDP PC(ppp) & -.062 & .957 \\
\hline Apmp & .222 & -.063 \\
\hline PPMP & .222 & .018 \\
\hline Rpmp & .235 & -.083 \\
\hline Ropmp & .194 & .177 \\
\hline WPMP & .216 & -.088 \\
\hline \multicolumn{2}{r}{$\begin{array}{l}\text { Extraction Method: Principal Component Analysis. } \\
\text { Rotation Method: Varimax with Kaiser Normalization. } \\
\text { Component Scores. }\end{array}$} \\
\hline
\end{tabular}

\section{Calculate the Z-score of Each Case}

Thus, scores of every case mating with each country can be computed with the formula: $\mathrm{z}$-score $=71.006 \%$ Fator $1+17.12 \%$ Factor2. After getting all 148 countries' $\mathrm{z}$-scores, rank all countries and then visualize and rank them in a radar chart in Figure.2.

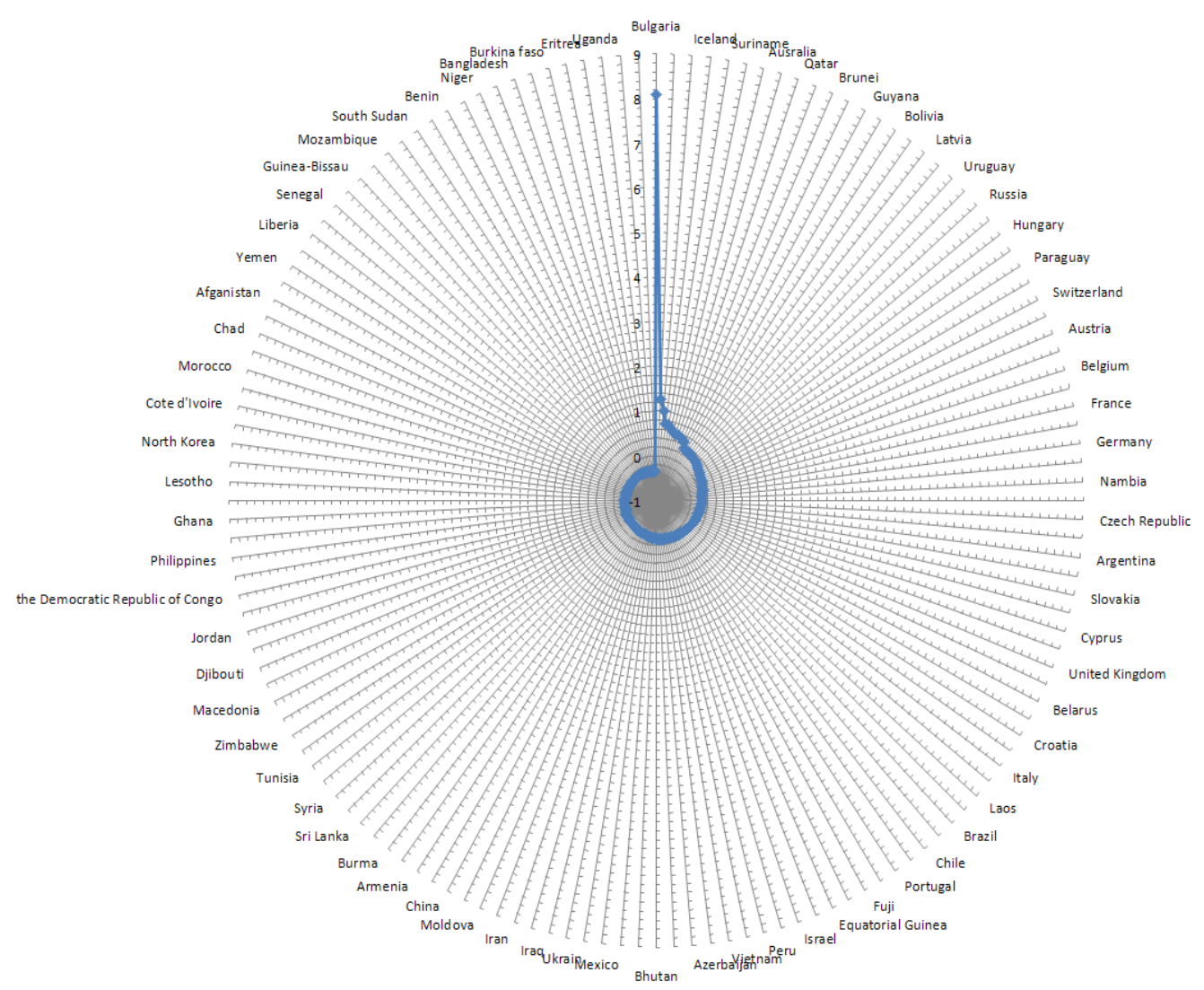

Figure.2 .Radar chart based on factor Scores of countries and their Rankings

\section{World Comparison}

The countries of the highest $\mathrm{z}$-scores are respectively Bulgaria(8.09), Finland(1.27), Iceland(1.01),United States(0.74), Suriname(0.73), Sweden(0.66), Australia(0.59) and Canada(0.55).Conversely, 20 countries of the smallest z-scores include Mali, Senegal, Tanzania, Guinea-Bissau, Madagascar, Mozambique, Somalia, South Sudan, Western Sahara, Benin, Malawi, Niger, Togo, Bangladesh, Nepal, Burkina Faso, Burundi, Eritrea, Ethiopia, Uganda and Rwanda, whose z-scores range from -0.31 to -0.34 , 
Rwanda's is the lowest of all the countries. The similar characteristics 20 countries share is that all of them are the poorest nations and their transportation indicators a million people are very small at the same time. China's ranking is 87 th with the -score of -0.21 , much lower than all developed countries whose scores are not less than -0.11 (Israel gets the lowest score in them). Malaysia, whose ranking is 57 th (-0.05) ranks ahead among all developing countries, even higher than several developed entities. On the whole, the real level of China's infrastructure development is in the middle class at most.

\section{Conclusion}

Although china has made much progress in transportation compared to its past since 1978, there is still a big gap between it and developed countries (even many developing ones). At present, it should keep attaching the importance to its transportation and upgrade infrastructure and increase the density per unit square kilometer or per person. In future, China's focus should still be on increasing the quantities and quality of transportation infrastructure and improving its people's living standard at the same time.

\section{Acknowledgments}

The research is part of a general project of Guangdong Philosophy and Social Sciences "the Twelfth- Five-year" Planning (GD11CGL01) and Doctor Startup Project of Huizhou University (C511.0118), which is granted by the relevant organizations in charge of them.

\section{References}

[1] H.Y. Cheng, D.Q. Li. Clustering Analysis of Chinese Water Transport Based on Importance Values. The proceedings of the 2009 International Conference on Information Management, Innovation Management and Industrial Engineering 4:43-46 (2009).

[2] CIA. https://www.cia.gov/library/publications/resources/the-world-factbook/

[3] National Bureau of Statistics of China. http://data.stats.gov.cn/easyquery.htm? $\underline{c n=C O 1}$ 